\title{
Human Taeniasis and Cysticercosis and Related Factors in Phu Tho Province, Northern Vietnam
}

\author{
Vu Thi Lam Binh ${ }^{1, \dagger} \oplus$, Do Trung Dung ${ }^{1, \dagger} \oplus$, Hoang Quang Vinh', Van Hul Anke², Praet Nicolas ${ }^{2,4}$, Dorny Pierre ${ }^{2,3}$, \\ Dermauw Veronique ${ }^{2, *}$ (i) \\ ${ }^{1}$ National Institute of Malariology, Parasitology and Entomology (NIMPE), No 34 Trung Van, Nam Tu Liem, Ha Noi, Vietnam; ${ }^{2}$ Department of \\ Biomedical Sciences, Institute of Tropical Medicine, Nationalestraat 155, 2000 Antwerpen, Belgium; 'Faculty of Veterinary Medicine, Ghent \\ University, Salisburylaan 133, 9820 Merelbeke, Belgium; ${ }^{4}$ The Janssen Pharmaceutical Companies of Johnson \& Johnson, Beerse, Belgium
}

\begin{abstract}
Several factors presumed to facilitate the transmission of Taenia spp. were reported in Vietnam. We conducted a cross-sectional study taking questionnaires from 1,185 participants, and collecting 1,151 sera and 1,036 stool samples in northern Vietnam. Sera were examined for circulating antigens of Taenia solium cysticerci using ELISA, stools for Taenia eggs by Kato-Katz smear, and copro-antigens by ELISA. Ag-ELISA revealed $4.6 \%$ antigen positivity, indicating infection with viable cysticerci. Taenia eggs were detected in 1.5\% of participants. Copro-antigens were found in $2.8 \%$ of participants. Eating raw meat and/or vegetables was significantly associated with the presence of copro-antigen $(\mathrm{OR}=8.6,95 \%$ $\mathrm{Cl}: 1.16-63.9, P=0.01)$. Considering the high taeniasis prevalence and the associated threat, public health attention should be given to treat the tapeworm carriers in the projected areas.
\end{abstract}

Key words: Taenia solium, Taenia spp., taeniasis, cysticercosis, copro-antigen, Vietnam

\section{INTRODUCTION}

Taenia solium was reported as the most important foodborne parasite in a risk assessment by the World Health Organization and the Food and Agricultural Organisation [1]. The parasite is endemic in many developing countries, including Vietnam. When consuming undercooked measled pork, humans can become infected with the adult tapeworm in their intestine, this condition is called taeniasis. When ingesting eggs by consuming contaminated vegetables, water or through bad hand hygiene [2], humans can acquire cysticercosis, infection with the cysticercus. Cysticerci can establish in the muscle, skin, and central nervous system [3]. Neurocysticercosis (NCC) is a serious cause of acquired epilepsy and accompanied symptoms in endemic countries $[3,4]$. Humans also act as the final host of T. saginata and T. asiatica. However, the occurrence of human cysticercosis is unique for T. solium infections [5].

In Vietnam, human taeniasis/cysticercosis cases have been reported in 60 of the 63 provinces [6,7]. Nevertheless, epide-

- Received 25 February 2021, revised 11 July 2021, accepted 19 July 2021.

*Corresponding author (vdermauw@itg.be)

${ }^{\dagger}$ These authors contributed equally to this work.

(c) 2021, Korean Society for Parasitology and Tropical Medicine

This is an Open Access article distributed under the terms of the Creative Commons Attribution Non-Commercial License (https://creativecommons.org/licenses/by-nc/4.0) which permits unrestricted non-commercial use, distribution, and reproduction in any

medium, provided the original work is properly cited. miological data on human taeniasis and cysticercosis only became available after 2000. Using classical coprology, the prevalence of taeniasis was estimated to range between 0 and 1.2\% [8-10]. Using more sensitive techniques such as copro-antigen detecting ELISA (coproAg-ELISA) and copro-PCR, prevalence estimates ranged between 0 and $6.7 \%[10,11]$. Apart from $T$. solium, T. asiatica and T. saginata infections are known to occur in the country [11,12], complicating the prevalence estimation of tapeworm carriers for the 3 separate species. Data on human cysticercosis are even more scarce for Vietnam. Each year, 200-300 cysticercosis patients have been treated in the referral clinic of the National Institute of Malariology, Parasitology and Entomology in Hanoi [13]. In northern Vietnam, the prevalence of circulating cysticercus antigens was reported to range between $0 \%$ and 5.7\% $[9,10]$. Among patients suffering from epilepsy in the North, the prevalence of active cysticercosis was estimated at $9 \%$ [14], while antibodies were measured in $5.0 \%$ of surveyed individuals in South and Central Vietnam $[11,15]$.

Vietnam has several factors presumed to facilitate the transmission of Taenia spp., such as the culinary habit to consume raw beef and pork [11], and the use of night soil to fertilize crops and vegetable fields [8]. Nevertheless, few epidemiological studies were conducted to investigate risk factors for Taenia spp. infections in Vietnam. It was reported that regular raw 
vegetable consumption, outdoor defecation, and drinking water from stream, lake, or pond are risk factors for cysticercosis, whereas being male and consuming undercooked pork or beef are for taeniasis [11]. In local reports, allowing pigs to roam freely, poor sanitation, lack of hygienic latrines, use of human feces as a fertilizer in agriculture, and no or inadequate meat inspection were identified as risk factors for taeniasis/cysticercosis [16].

To address the scarcity of epidemiological data on human taeniasis and cysticercosis in the country, we conducted a study in 3 communes in Phu Tho Province, representative for northern Vietnam. This area is mountainous, inhabited predominantly by ethnic minorities farming pigs, both traditional and commercial types. The local people have a habit of eating raw pork and vegetables. The purpose of our study was to determine the prevalence of taeniasis and cysticercosis and to assess the risk factors associated with T. solium infection.

\section{MATERIALS AND METHODS}

\section{Ethical clearance}

The study was approved by the Ministry of Health, Vietnam
(314/QD-BYT). Prior to actual data collection, health staff visited the projected areas, and informed inhabitants about the study aims through a loudspeaker system. The written consent was obtained from all willing, eligible participants prior to information and/or sample collection. For individuals below 16-year-old, permission was obtained from their parents or guardians by means of a written informed consent. All study documents were stored at National Institute of Malariology, Parasitology and Entomology (NIMPE), Hanoi, Vietnam. Results were handled confidentially, and privacy of participants was assured. All people who had positive stool or serological test results were treated according to the guidelines of the Ministry of Health, Vietnam.

\section{Study design and area}

A cross-sectional survey was conducted from August 2012 to December 2012 in 3 communes of Phu Tho Province, $120 \mathrm{~km}$ away from Hanoi, capital of Vietnam (Fig. 1). Thu Ngac commune comprises of 15 hamlets and 5,552 inhabitants in 1,150 households. Long Coc commune, bordering with Thu Ngac commune, has 8 hamlets, and 3,133 people in 766 households. Xuan Vien commune consists of 13 hamlets, with 4,596

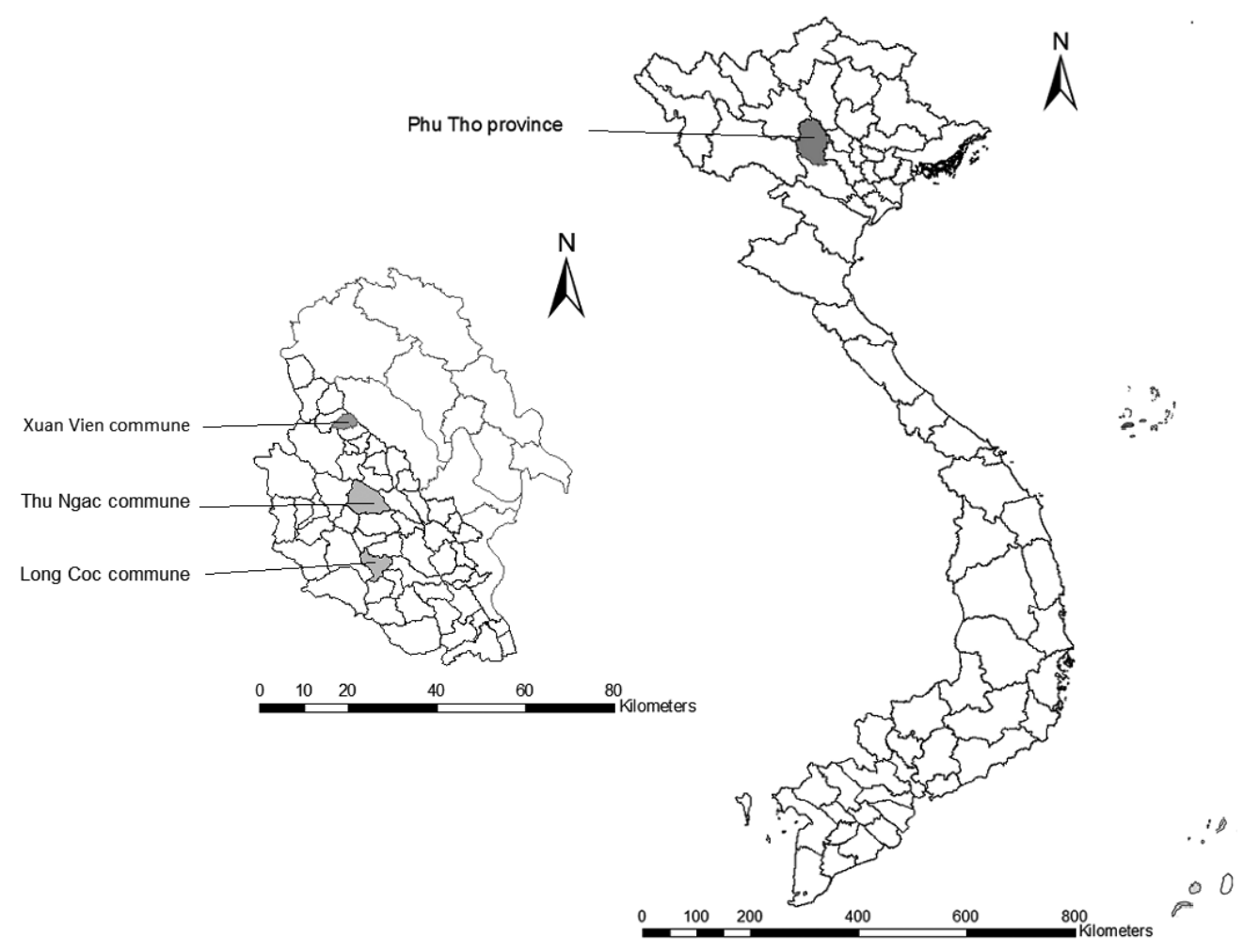

Fig. 1. Map of Vietnam showing Phu Tho Province and the surveyed communes. 
people in 1,173 households. Citizens in the 3 communes are predominantly Muong (95-99\%) ethnic minority group. Commune selection was based on a high number of neurocysticercosis (NCC) patients treated at NIMPE, the presence of taeniasis cases, and the habit of eating undercooked pork in the area (unpublished survey data).

\section{Sampling}

Prior to collecting data, households were randomly chosen, and participants were randomly selected from the chosen households. The survey communities were informed about the study goals using the local loudspeaker system. For collecting information, selected individuals were approached, the study aims and procedures were explained, and eligible individuals were formally invited to participate in the study. Individuals were excluded when being pregnant, suffering from severe chronic or acute diseases, being younger than 6 years old, or being above 65 years old. The envisaged sample size was 384 people for each commune (1,152 in total), assuming a large population size with unknown prevalence and setting the required confidence level at 95\% with 5\% precision [17].

All consenting participants were given a zip-bag with a label for self-collecting the stool sample. On the next day, stool samples were brought to the commune health centre. In addition, blood was sampled from the participants using $5 \mathrm{ml}$ plain tubes. Finally, the participants were asked to respond to a questionnaire, capturing data on demography, eating behaviour, toilet use, and history of taeniasis/cysticercosis-related signs or symptoms. The questionnaire was pretested prior to the data collection.

Collected stool samples were stored in a cool box for immediate coproscopy, while an aliquot was fixed in 10\% formalin solution at 1:1 ratio for copro-antigen detection. Blood samples were clotted, and sera were collected. The sera were stored at $-40^{\circ} \mathrm{C}$ until use.

\section{Laboratory analyses}

Stool samples were examined for parasite eggs (coproscopy) using Kato-Katz smear following the WHO protocol [18]. Taenia antigens in the stool samples were analysed using an inhouse polyclonal antibody-based copro-antigen ELISA (coproAg-ELISA) as described previously [19] with some modifications [20]. A cut-off of optical density (OD) was set at a mean OD of 8 Taenia-negative stool samples plus 3 standard deviations. Copro-antigen positive results indicate the presence of an adult Taenia spp., thus taeniasis.

Blood samples were analyzed for the excretory-secretory circulating antigens of the cysticerci of T. solium using a monoclonal antibody-based B158/B60 antigen ELISA (Ag-ELISA) [21]. A cut-off of OD was set at a mean OD of 8 reference negative human sera $(P=0.001)$. Antigen positive results indicate presence of viable cysticerci, thus active cysticercosis.

\section{Data analysis}

The data collected were analyzed using Excel and EpiData software (version 3.1, EpiData Association, Odense, Denmark). A descriptive analysis was run first for association between commune and demographic characteristics of participants. Then, the association between copro-Ag-ELISA and serum Ag-ELISA results, and demographic factors and questionnaire responses, was investigated. Associations were analyzed using the Pearson's chi-square test, and the cases showing cell counts below 5, using the Fisher's exact test. Associated odds ratio and confidence intervals were calculated. Statistical significance was set at $P<0.05$ level. All statistical analyses were conducted using $\mathrm{R}$, a language and environment for statistical computing (R Foundation for Statistics, version 4.0.3, Vienna, Austria) [22].

\section{RESULTS}

A total of 1,185 people (515 men and 670 women) participated in this study (Table 1). All but 26 individuals belonged to the Muong ethnic minority (97.8\%), the others to the Kinh group. The majority of participants were 21-50 years old (56.7\%), and their main occupation was farming (76.7\%). Commune and demographic characteristics were significantly associated $(P>0.05)$, except for ethnicity $(P=0.462)$. All 1,185 participants responded to the questionnaire, while serum samples were collected from 1,151 individuals. Stool samples were collected from 1,036 participants, of which 925 were examined using the copro-Ag-ELISA.

A large majority of participants declared to consume raw meat and/or vegetables (76.9\%) (Table 2). Fifteen cases (1.3\%) reported having subcutaneous nodules, while $15.4 \%$ participants had observed proglottids in their stools. A total of 32 participants $(2.7 \%)$ mentioned that they were suffering from epilepsy. In Thu Ngac, a high percentage of participants reported having seen proglottids in their stools, or reported suffering from epilepsy, in comparison with the other two 
Table 1. Demographic characteristics of participants in Phu Tho Province, Vietnam $(n=1,185)$

\begin{tabular}{|c|c|c|c|c|c|c|c|c|}
\hline \multirow{2}{*}{ Variable } & \multicolumn{2}{|c|}{ Long Coc } & \multicolumn{2}{|c|}{ Thu Ngac } & \multicolumn{2}{|c|}{ Xuan Vien } & \multicolumn{2}{|c|}{ Total } \\
\hline & $n$ & $\%$ & $n$ & $\%$ & $\mathrm{n}$ & $\%$ & $n$ & $\%$ \\
\hline \multicolumn{9}{|l|}{ Gender } \\
\hline Male & 203 & 54.1 & 178 & 45.8 & 134 & 31.8 & 515 & 43.5 \\
\hline Female & 172 & 45.9 & 211 & 54.2 & 287 & 68.2 & 670 & 56.5 \\
\hline & \multicolumn{8}{|c|}{$P<0.001$} \\
\hline \multicolumn{9}{|l|}{ Occupation } \\
\hline Farmer & 289 & 77.1 & 305 & 78.4 & 317 & 75.3 & 911 & 76.9 \\
\hline Worker & 13 & 3.5 & 9 & 2.3 & 3 & 0.71 & 25 & 2.1 \\
\hline Civil servant & 66 & 17.6 & 72 & 18.5 & 101 & 24.0 & 239 & 20.2 \\
\hline \multirow[t]{2}{*}{ Other } & 7 & 1.87 & 3 & 0.77 & 0 & 0 & 10 & 0.84 \\
\hline & \multicolumn{8}{|c|}{$P=0.001$} \\
\hline \multicolumn{9}{|l|}{ Age group } \\
\hline$\leq 10$ & 19 & 5.1 & 30 & 7.7 & 78 & 18.5 & 127 & 10.7 \\
\hline $11-20$ & 69 & 18.4 & 54 & 13.9 & 63 & 15 & 186 & 15.7 \\
\hline $21-30$ & 80 & 21.3 & 86 & 22.1 & 58 & 13.8 & 224 & 18.9 \\
\hline $31-40$ & 84 & 22.4 & 82 & 21.1 & 69 & 16.4 & 235 & 19.8 \\
\hline $41-50$ & 68 & 18.1 & 75 & 19.3 & 70 & 16.6 & 213 & 18.0 \\
\hline $51-60$ & 40 & 10.7 & 47 & 12.1 & 58 & 13.8 & 145 & 12.2 \\
\hline \multirow[t]{2}{*}{$>60$} & 15 & 4.0 & 15 & 3.9 & 25 & 5.9 & 55 & 4.6 \\
\hline & \multicolumn{8}{|c|}{$P<0.001$} \\
\hline Total & 375 & 100 & 389 & 100 & 421 & 100 & 1,185 & 100 \\
\hline
\end{tabular}

Table 2. Questionnaire results of participants in Phu Tho Province, Vietnam $(n=1,185)$

\begin{tabular}{|c|c|c|c|c|c|c|c|c|}
\hline \multirow{2}{*}{ Variable } & \multicolumn{2}{|c|}{ Long Coc } & \multicolumn{2}{|c|}{ Thu Ngac } & \multicolumn{2}{|c|}{ Xuan Vien } & \multicolumn{2}{|c|}{ Total } \\
\hline & $\mathrm{n}$ & $\%$ & $n$ & $\%$ & $n$ & $\%$ & $\mathrm{n}$ & $\%$ \\
\hline \multicolumn{9}{|c|}{ Raw meat and/or vegetable consumption } \\
\hline Yes & 296 & 78.9 & 318 & 81.8 & 297 & 70.6 & 911 & 76.9 \\
\hline \multirow[t]{2}{*}{ No } & 79 & 21.1 & 71 & 18.3 & 124 & 29.5 & 274 & 23.1 \\
\hline & \multicolumn{8}{|c|}{$P<0.001$} \\
\hline \multicolumn{9}{|c|}{ Presence of subcutaneous nodules } \\
\hline Yes & 4 & 1.07 & 7 & 1.8 & 4 & 0.95 & 15 & 1.27 \\
\hline \multirow[t]{2}{*}{ No } & 371 & 98.9 & 382 & 98.2 & 417 & 99.1 & 1,170 & 98.7 \\
\hline & \multicolumn{8}{|c|}{$P=0.55$} \\
\hline \multicolumn{9}{|c|}{ Proglottids seen in stools } \\
\hline Yes & 40 & 10.7 & 129 & 33.2 & 14 & 3.3 & 183 & 15.4 \\
\hline \multirow[t]{2}{*}{ No } & 335 & 89.3 & 260 & 66.8 & 407 & 96.7 & 1,002 & 84.6 \\
\hline & \multicolumn{8}{|c|}{$P<0.001$} \\
\hline \multicolumn{9}{|l|}{ Epilepsy } \\
\hline Yes & 5 & 1.33 & 24 & 6.2 & 3 & 0.71 & 32 & 2.7 \\
\hline \multirow[t]{2}{*}{ No } & 370 & 98.7 & 365 & 93.8 & 418 & 99.3 & 1,153 & 97.3 \\
\hline & \multicolumn{8}{|c|}{$P<0.001$} \\
\hline
\end{tabular}

communes. An association between questionnaire response and commune was observed for eating raw meat/vegetables, proglottids seen in faeces, and reporting to suffer from epilepsy (all $P<0.05)$.

Taenia spp. eggs were found in $1.5 \%$ of the stool samples (Table 3). No participant was found infected with Taenia spp. in Xuan Vien commune, while there were 1.7\% and 3.1\% infected cases in Long Coc and Thu Ngac communes, respectively. Almost all taeniasis cases were males (81.3\%), and they were all over 10 years old.

Positive copro-Ag-ELISA results were found in $2.9 \%$ of participants, $3.8 \%$ in males, $2.3 \%$ in females (Table 4 ). No associ- 


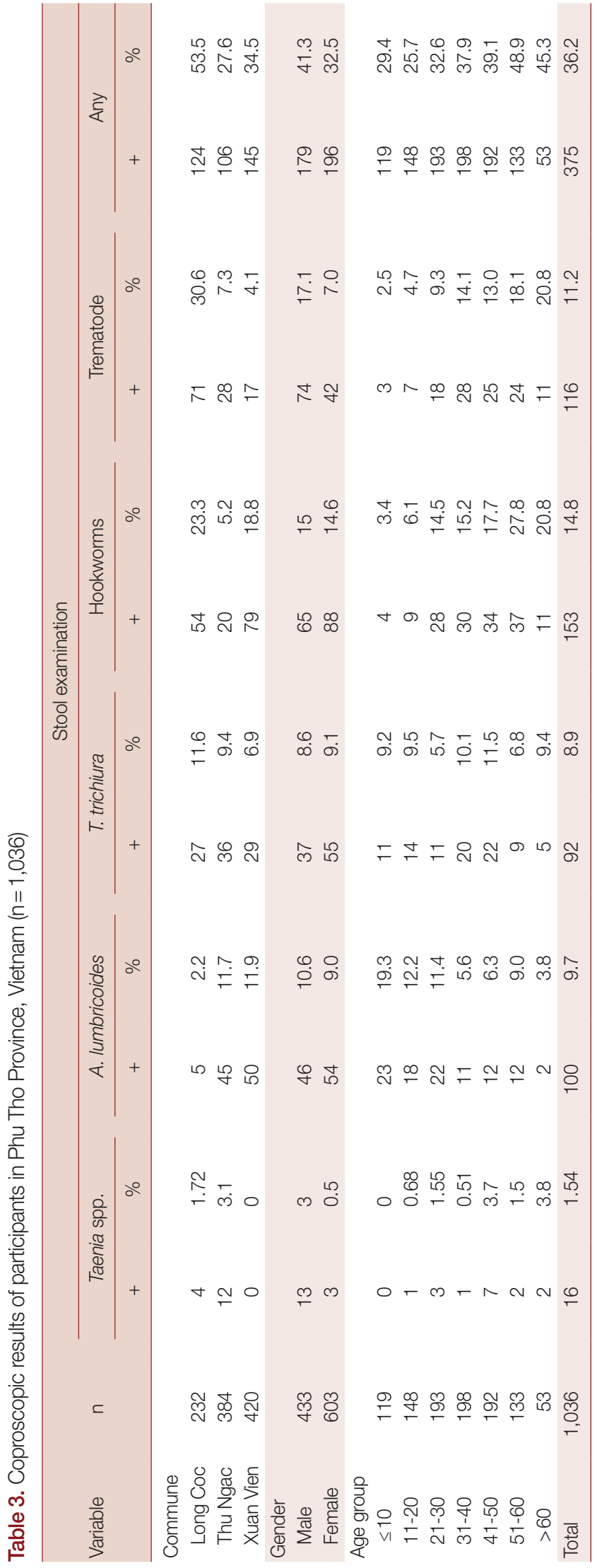

ation was found between commune, gender or age group and copro-Ag-ELISA result (all $P>0.05$ ). A strong association was found between eating raw meat and/or vegetables and having a positive result in the copro-Ag-ELISA. There was a high uncertainty around this estimate ( $\mathrm{OR}=8.6,95 \% \mathrm{CI}$ : 1.16-63.9, $P=0.01$ ) (Table 4). No significant associations were found between having observed proglottids in feces and positivity in Copro-Ag-ELISA $(P>0.05)$, although there was a trend in that direction ( $\mathrm{OR}=2.2,95 \% \mathrm{CI}: 0.93-5.1)$. For 24 out of 25 cases with positive copro-Ag-ELISA, there was a negative coproscopy result, whereas 14 out of 15 people with a positive coproscopy result had a negative copro-Ag-ELISA result.

The antigen positive prevalence in sera, indicating infections with viable cysticerci, was $4.6 \%, 3.6 \%$ in males and $5.4 \%$ in females (Table 5). No association was found between communes, genders or age groups, and Ag-ELISA results (all $P>0.05$ ). No significant associations were found between questionnaire responses and the positivity of Ag-ELISA (all $P>0.05$ ).

\section{DISCUSSION}

A higher prevalence of taeniasis was observed in the study areas compared to the earlier studies [8-10]. Using the more sensitive copro-PCR test, a higher taeniasis prevalence was reported [11] in Central Vietnam. In contrast to the higher prevalence of taeniasis, a lower prevalence of soil-transmitted helminths (STH) was observed than in earlier studies [8-10]. This disparate trend for taeniasis versus other parasites, could point to a general improvement in hygienic conditions and/or mass drug administration programmes in the area, yet with continued risky behavior in terms of culinary habits consuming raw meat.

There was a marked difference in taeniasis prevalence based on coproscopy and copro-Ag-ELISA. This is due to disparity in test sensitivity, for coproscopy at $52.4 \%$ and for copro-Ag-ELISA at $84.5 \%$ [23]. Furthermore, test specificity might be problematic for the copro-Ag-ELISA [23] due to the presence of cross-reactions with other parasites, although earlier work failed to detect such cross-reactions $[19,24]$. In addition, Praet et al. [23] pointed to the ability of the copro-Ag-ELISA to detect immature tapeworm stages. These 3 hypotheses might explain why 24 out of 25 stool samples with a positive coproAg-ELISA result, had a negative coproscopy result. On the other hand, 14 out of 15 people with a positive coproscopy result 
Table 4. Association between copro-Ag-ELISA results and questionnaire responses in Phu Tho Province, Vietnam $(n=885)$

\begin{tabular}{|c|c|c|c|c|c|c|}
\hline \multirow{2}{*}{ Variable } & \multicolumn{6}{|c|}{ Copro-Ag-ELISA } \\
\hline & $\mathrm{n}$ & + & $\%$ & OR & $95 \% \mathrm{Cl}$ & $P$ \\
\hline \multicolumn{7}{|l|}{ Commune } \\
\hline Long Coc & 188 & 5 & 2.7 & 1 & & \\
\hline Thu Ngac & 301 & 10 & 3.3 & 1.25 & $0.42-3.7$ & 0.68 \\
\hline Xuan Vien & 396 & 11 & 2.8 & 1.05 & $0.35-3.1$ & 0.94 \\
\hline \multicolumn{7}{|l|}{ Gender } \\
\hline Female & 519 & 12 & 2.3 & 1 & & \\
\hline Male & 366 & 14 & 3.8 & 1.68 & $0.77-3.7$ & 0.19 \\
\hline \multicolumn{7}{|l|}{ Age group } \\
\hline$\leq 10$ & 107 & 4 & 3.7 & 1 & & \\
\hline $11-20$ & 120 & 1 & 0.8 & 0.22 & $0.02-1.97$ & 0.19 \\
\hline $21-30$ & 159 & 7 & 4.4 & 1.19 & $0.34-4.2$ & 1 \\
\hline $31-40$ & 170 & 5 & 2.9 & 0.78 & $0.20-3.0$ & 0.74 \\
\hline $41-50$ & 168 & 7 & 4.2 & 1.12 & $0.32-3.9$ & 1 \\
\hline $51-60$ & 115 & 1 & 0.9 & 0.22 & $0.02-2.1$ & 0.2 \\
\hline$>60$ & 43 & 0 & 0 & - & - & 0.58 \\
\hline \multicolumn{7}{|c|}{ Raw meat and/or vegetable consumption } \\
\hline No & 221 & 1 & 0.4 & 1 & & \\
\hline Yes & 664 & 25 & 3.8 & 8.6 & $1.16-63.9$ & 0.01 \\
\hline \multicolumn{7}{|c|}{ Proglottids seen in stools } \\
\hline No & 732 & 18 & 2.5 & 1 & & \\
\hline Yes & 153 & 8 & 5.2 & 2.2 & $0.93-5.1$ & 0.07 \\
\hline Total & 885 & 26 & 2.9 & & & \\
\hline
\end{tabular}

Table 5. Association between Ag-ELISA results and questionnaire responses in Phu Tho Province, Vietnam $(n=1,151)$

\begin{tabular}{|c|c|c|c|c|c|c|}
\hline \multirow{2}{*}{ Variable } & \multicolumn{6}{|c|}{ Ag-ELISA } \\
\hline & $\mathrm{n}$ & + & $\%$ & OR & $95 \% \mathrm{Cl}$ & $P$ \\
\hline \multicolumn{7}{|l|}{ Commune } \\
\hline Long Coc & 364 & 17 & 4.7 & 1 & & \\
\hline Thu Ngac & 389 & 17 & 4.4 & 0.93 & $0.47-1.86$ & 0.84 \\
\hline Xuan Vien & 398 & 19 & 4.8 & 1.02 & $0.52-2.00$ & 0.95 \\
\hline \multicolumn{7}{|l|}{ Gender } \\
\hline Female & 646 & 35 & 5.4 & 1 & & \\
\hline Male & 505 & 18 & 3.6 & 0.65 & $0.36-1.15$ & 0.14 \\
\hline \multicolumn{7}{|l|}{ Age group } \\
\hline$\leq 10$ & 122 & 7 & 5.7 & 1 & & \\
\hline $11-20$ & 180 & 8 & 4.4 & 0.76 & $0.27-2.2$ & 0.61 \\
\hline $21-30$ & 218 & 5 & 2.3 & 0.39 & $0.12-1.20$ & 0.11 \\
\hline $31-40$ & 232 & 13 & 5.6 & 0.98 & $0.38-2.5$ & 0.96 \\
\hline $41-50$ & 207 & 12 & 5.8 & 1.01 & $0.39-2.6$ & 0.98 \\
\hline $51-60$ & 139 & 4 & 2.9 & 0.49 & $0.14-1.70$ & 0.26 \\
\hline$>60$ & 53 & 4 & 7.6 & 1.34 & $0.38-4.8$ & 0.65 \\
\hline \multicolumn{7}{|c|}{ Raw meat and/or vegetable consumption } \\
\hline No & 265 & 17 & 6.4 & 1 & & \\
\hline Yes & 886 & 36 & 4.1 & 0.6 & $0.34-1.12$ & 0.11 \\
\hline \multicolumn{7}{|c|}{ Presence of subcutaneous nodules } \\
\hline No & 1,136 & 53 & 4.7 & 1 & & \\
\hline Yes & 15 & 0 & 0 & - & - & 1 \\
\hline \multicolumn{7}{|l|}{ Epilepsy } \\
\hline No & 1,119 & 51 & 4.6 & 1 & & \\
\hline Yes & 32 & 2 & 6.3 & 1.4 & $0.32-6.0$ & 0.65 \\
\hline Total & 1,151 & 53 & 4.6 & & & \\
\hline
\end{tabular}


had a negative copro-Ag-ELISA result. This disagreement might be explained by the presence of T. saginata and/or T. asiatica infections, which produce weaker reactions in the current coproAg-ELISA [26], thus causing a negative copro-Ag-ELISA result, but positive coproscopy result. In the current study, we did not differentiate Taenia spp., so we could not investigate whether the presence of T. saginata and/or T. asiatica infections played a role in this difference in test results.

The prevalence of active cysticercosis as examined by Ag-ELISA was in line with earlier reports in rural and mountainous regions in northern Vietnam $[9,10]$. Prevalence of cysticercosis antibodies was 5.0\% in Central Vietnam [11] and 4.9\% in South Vietnam $[15,27]$. Prevalence of active cysticercosis in Vietnamese patients suffering from epilepsy was estimated at $9 \%[14]$, showing that a significant proportion of epilepsy cases could be attributed to neurocysticercosis. In this study, 2.7\% of participants reported epilepsy, no significant association with Ag-ELISA results was found. This could be due to the small number of participants reporting epilepsy.

In Vietnam, being male, consuming undercooked pork or beef, and having observed proglottids in the stool were significantly associated with taeniasis [11], confirmed in our study. Moreover, regular consumption of raw vegetables, outdoor defecation, drinking from streams, lakes, or ponds all were found to be significantly associated with the presence of antibodies [11], while no factors were significantly associated with active cysticercosis in our study. These findings point to the need to perform more in-depth studies investigated on risk factors for taeniasis/cysticercosis in North Vietnam, in order to adequately address both conditions in the region.

Our study has some limitations. First, the lack of species identification is hampering an in-depth insight on Taenia spp. epidemiology in the region. In Vietnam, 3 Taenia spp. cause human taeniasis, T. solium, T. saginata, and T. asiatica, and a recent study has also confirmed the presence of $T$. asiatica in pigs in Phu Tho Province [28]. This problem should be addressed in future studies by using molecular techniques. Furthermore, the pooled questions about raw vegetable and meat consumption might impact study conclusions.

In conclusion, notwithstanding the improvement of hygienic standards and living conditions in Vietnam in last decades, our study has shown that T. solium transmission still occurs in communities in Phu Tho Province. The consumption of raw pork and vegetables combined with traditional pig husbandry systems, poor meat inspection procedures [28,29], and the common habit of using night soil on agricultural lands [8] are likely to perpetuate the transmission of tapeworm infections. Health education campaigns are needed in this area to inform the population on those infection risks.

\section{ACKNOWLEDGMENTS}

We would like to thank field staffs and study participants. This work was supported by the Belgian Directorate-General for Development Cooperation (DGD) within the DGD-ITM Framework Agreement 3.

\section{CONFLICT OF INTEREST}

The authors declare no conflict of interest.

\section{REFERENCES}

1. Food and Agriculture Organization of the United Nations, World Health Organization. Multicriteria-Based Ranking for Risk Management of Food-Borne Parasites. FAO Headquarters. Rome, Italy. 2014.

2. Carpio A. Review Neurocysticercosis : an update. Lancet Infect Dis 2002;2:751-762. https://doi.org/10.1016/s1473-3099(02)00454-1

3. García HH, Gonzalez AE, Evans CA, Gilman RH. Taenia solium cysticerosis. Lancet 2003; 362: 547-556. https://doi.org/10.1016/ S0140-6736(03)14117-7

4. Carabin H, Ndimubanzi PC, Budke CM, Nguyen H, Qian Y, Cowan LD, Stoner JA, Rainwater E, Dickey M. Clinical manifestations associated with neurocysticercosis: A systematic review. PLoS Negl Trop Dis 2011; 5: e1152. https://doi.org/10.1371/journal. pntd.0001152

5. Dorny P, Praet N, Deckers N, Gabriel S. Emerging food-borne parasites. Vet Parasitol 2009; 163: 196-206. https://doi.org/10.1016/ j.vetpar.2009.05.026

6. Bernard PN, Bablet J, Pons R. Les vers intestinaux en Cochinchine. Bull Soc Path exot 1924; 17: 577-582 (in French).

7. Ng-Nguyen D, Stevenson MA, Traub RJ. A systematic review of taeniasis, cysticercosis and trichinellosis in Vietnam. Parasit Vectors. Parasit Vectors; 2017; 10: 150. https://doi.org/10.1186/s13071-0172085-9

8. Verle P, Kongs A, De NV, Thieu NQ, Depraetere K, Kim HT, Dorny P. Prevalence of intestinal parasitic infections in northern Vietnam. Trop Med Int Health 2003; 8: 961-964. https://doi.org/10.1046/ j.1365-3156.2003.01123.x

9. Erhart A, Dorny P, Van De N, Vien HV, Thach DC, Toan ND, Cong le D, Geerts S, Speybroeck N, Berkvens D, Brandt J. Taenia solium cysticercosis in a village in northern Viet Nam: sero-prevalence study using an ELISA for detecting circulating antigen. Trans R Soc Trop Med Hyg 2002; 96: 270-272. https://doi.org/10.1016/ 
s0035-9203(02)90095-7

10. Somers R, Dorny P, Nguyen VK, Dang TC, Goddeeris B, Craig PS, Vercruysse J. Taenia solium taeniasis and cysticercosis in three communities in north Vietnam. Trop Med Int Health 2006; 11: 65-72. https://doi.org/10.1111/j.1365-3156.2005.01537.x

11. Ng-Nguyen D, Stevenson MA, Breen K, Phan TV, Nguyen VT, Vo TV, Traub RJ. The epidemiology of Taenia spp. infection and Taenia solium cysticerci exposure in humans in the Central Highlands of Vietnam. BMC Infect Dis. BMC Infect Dis 2018; 18: 527. https://doi.org/ 10.1186/s12879-018-3434-9

12. Somers R, Dorny P, Geysen D, Nguyen LA, Thach DC, Vercruysse J, Nguyen VK. Human tapeworms in north Vietnam. Trans R Soc Trop Med Hyg 2007; 101: 275-257. https://doi.org/10.1016/ j.trstmh.2006.04.007

13. De N Van, Le TH, Lien PTH, Eom KS. Current Status of Taeniasis and Cysticercosis in Vietnam. Korean J Parasitol 2014; 52: 125129. https://doi.org/10.3347/kjp.2014.52.2.125

14. Trung DD, Praet N, Cam TD, Lam BV, Manh HN, Gabriël S, Dorny P. Assessing the burden of human cysticercosis in Vietnam. Trop Med Int Health 2013; 18: 352-356. https://doi.org/10.1111/ tmi.12043

15. Nguyen T, Cheong FW, Liew JWK, Lau YL. Seroprevalence of fascioliasis, toxocariasis, strongyloidiasis and cysticercosis in blood samples diagnosed in Medic Medical Center Laboratory, Ho Chi Minh City, Vietnam in 2012. Parasit Vectors 2016; 9: 486. https://doi.org/10.1186/s13071-016-1780-2

16. Trieu HS. Study on genotype of pathogen, clinical, sub-clinical symptoms, treatment efficacy for taeniasis and cysticercosis patients in National Institute of Malariology, Parasitology and Entomology 2007-2010. PhD thesis. 2012 (in Vietnamese).

17. Lemeshow S, DW Hosmer Jr, Klar J, Lwanga SK. Adequacy of Sample Size in Health Studies. Chichester, England. John Wiley \& Sons. 1990. https://apps.who.int/iris/handle/10665/41607

18. World Health Organization. Basic Laboratory Methods in Medical Parasitology. Geneva, Switzerland. World Health Organization. 1991.

19. Allan JC, Avila G, Garcia Noval J, Flisser A, Craig PS. Immunodiagnosis of taeniasis by coproantigen detection. Parasitology 1990; 101: 473-477. https://doi.org/10.1017/s0031182000060686

20. Mwape KE, Phiri IK, Praet N, Muma JB, Zulu G, Van den Bossche P, de Deken R, Speybroeck N, Dorny P, Gabriël S. Taenia solium infections in a rural area of Eastern Zambia-a community based study. PLoS Negl Trop Dis 2012; 6: e1594. https://doi.org/10.1371/jour- nal.pntd.0001594

21. Dorny P, Phiri IK, Vercruysse J, Gabriel S, Willingham AL 3rd, Brandt J, Victor B, Speybroeck N, Berkvens D. A Bayesian approach for estimating values for prevalence and diagnostic test characteristics of porcine cysticercosis. Int J Parasitol 2004; 34: 569-576. https://doi.org/10.1016/j.ijpara.2003.11.014

22. R Core Team. R: A Language and Environment for Statistical Computing. Vienna, Austria. R Foundation for Statistical Computing. 2020. http://www.r-project.org/index.html

23. Praet N, Verweij JJ, Mwape KE, Phiri IK, Muma JB, Zulu G, van Lieshout L, Rodriguez-Hidalgo R, Benitez-Ortiz W, Dorny P, Gabriël S. Bayesian modelling to estimate the test characteristics of coprology, coproantigen ELISA and a novel real-time PCR for the diagnosis of taeniasis. Trop Med Int Health 2013; 18: 608614. https://doi.org/10.1111/tmi.12089

24. Allan JC, Velasquez-Tohom M, Torres-Alvarez R, Yurrita P, GarciaNoval J. Field trial of the coproantigen-based diagnosis of Taenia solium taeniasis by enzyme-linked immu- nosorbent assay. Am J Trop Med Hyg 1996; 54: 352-356. https://doi.org/10.4269/ajtmh. 1996.54.352

25. Tembo A, Craig PS. Taenia saginata taeniosis: copro-antigen time-course in a voluntary self-infection. J Helminthol 2015; 89: 612-619. https://doi.org/10.1017/S0022149X14000455

26. Ng-Nguyen D, Stevenson MA, Dorny P, Gabriël S, Vo TV, Nguyen VT, Phan TV, Hii SF, Traub RJ. Comparison of a new multiplex real-time PCR with the Kato Katz thick smear and coproantigen ELISA for the detection and differentiation of Taenia spp. in human stools. PLoS Negl Trop Dis 2017; 11: 1-18. https://doi. org/10.1371/journal.pntd.0005743

27. Garcia HH, Castillo Y, Gonzales I, Bustos JA, Saavedra H, Jacob L, Del Brutto OH, Wilkins PP, Gonzalez AE, Gilman RH. Low sensitivity and frequent cross-reactions in commercially available antibody detection ELISA assays for Taenia solium cysticercosis. Trop Med Int Health 2018; 23: 101-105. https://doi.org/10.1111/ tmi.13010

28. Nguyen TTM, Dermauw V, Noh J, Chien NH, Dao TTH, Nguyen TGT, Van Hul A, Dorny P. Occurrence of Taenia species in pigs in slaughterhouses in Phu Tho Province, northern Vietnam. J Helminthol 2020; 94: e201. https://doi.org/10.1017/S0022149X20000863

29. Nguyen Thi Thuy M, Dorny P, Lebailly P, Le Thi Minh C, Nguyen Thi Thu H, Dermauw V. Mapping the pork value chain in Vietnam : a systematic review. Trop Anim Health Prod 2020; 52: 2799-2808. https://doi.org/10.1007/s11250-020-02338-y 